\title{
Negative pressures in full-scale distribution system: field investigation, modelling, estimation of intrusion volumes and risk for public health
}

\author{
M. C. Besner ${ }^{1}$, G. Ebacher ${ }^{1}$, B. S. Jung ${ }^{2}$, B. Karney ${ }^{3}$, J. Lavoie ${ }^{4}$, P. Payment ${ }^{5}$, and M. Prévost ${ }^{1}$ \\ ${ }^{1}$ Ecole Polytechnique de Montreal, Civil, Geological and Mining Engineering Dept, CP 6079, \\ Succ. Centre-ville, Montréal (Québec), H3C 3A7, Canada \\ ${ }^{2}$ MWH Soft Inc., 618 Michillinda Avenue, Suite 200, Arcadia, California, 91007, USA \\ ${ }^{3}$ Univ. of Toronto, Department of Civil Engineering, 35 St.George St., Toronto (Ontario), M5S 1A4, Canada \\ ${ }^{4}$ City of Laval, Service de l'environnement, 2550 boul. Industriel, Laval (Québec), H7V 3Z4, Canada \\ ${ }^{5}$ INRS-Institut Armand-Frappier, 531 boul. des Prairies, Laval (Québec), H7V 1B7, Canada
}

Received: 10 February 2010 - Published in Drink. Water Eng. Sci. Discuss.: 12 March 2010

Revised: 29 June 2010 - Accepted: 8 July 2010 - Published: 16 July 2010

\begin{abstract}
Various investigations encompassing microbial characterization of external sources of contamination (soil and trenchwater surrounding water mains, flooded air-valve vaults), field pressure monitoring, and hydraulic and transient analyses were conducted in the same distribution system where two epidemiological studies showing an increase in gastrointestinal illness for people drinking tap water were conducted in the 1990's. Interesting results include the detection of microorganisms indicators of fecal contamination in all external sources investigated but at a higher frequency in the water from flooded air-valve vaults, and the recording of 18 negative pressure events in the distribution system during a 17-month monitoring period. Transient analysis of this large and complex distribution system was challenging and highlighted the need to consider field pressure data in the process.
\end{abstract}

\section{Introduction}

For the last few years, the topic of microbial intrusion in distribution systems has been investigated by the NSERC Industrial Chair on Drinking Water at Ecole Polytechnique de Montreal. Since 2004, our team and various collaborators have been awarded three successive research projects funded by the Canadian Water Network, during which various investigations encompassing microbial characterization of external sources of contamination, field pressure monitoring, hydraulic and transient analyses, and risk assessment modeling were conducted or are still in progress.

One of the main concerns related to the occurrence of transient negative pressure events in distribution systems is the potential for contamination associated with the intrusion of contaminated water through pipe leaks or other types of orifices. In order to assess the public health significance of such

Correspondence to: M. C. Besner (mcbesner@polymtl.ca) events, parameters such as the frequency and the magnitude of negative pressure events, the level of microbial contamination from various sources or pathways, and the volumes of contaminated water intruded into the system are needed. While it is possible to conduct field characterization to estimate some of these parameters in full-scale distribution systems, some other inputs such as intrusion volumes may only be assessed using hydraulic, especially transient analysis, modeling.

Previous studies have shown that low or negative pressure events are not uncommon in distribution systems (Kirmeyer et al., 2001; LeChevallier et al., 2004; Gullick et al., 2004, 2005; Hooper et al., 2006) and that the soil and water surrounding water mains may contain fecal contamination and viruses (Karim et al., 2003). Aging drinking water infrastructure certainly provides some potential pathway for contaminant intrusion. A grade of D- has been awarded to US drinking water infrastructures (ASCE, 2009). Water losses between 8 to $24 \%$ of the water supplied (unaccounted for water) have been estimated for developed countries based on 1991 data (WHO, 2001) and higher values are now commonly 
reported. The fraction of water strictly lost through pipe leaks is not always available but in Canada, it is estimated that up to $30 \%$ of the total water entering supply-line systems is lost to leaking pipes (Environment Canada, 2010).

It has been hypothesized (NRC, 2006), that intrusion events could be related to the increase in gastrointestinal illnesses observed by Payment et al. $(1991,1997)$ in their two epidemiological studies of a Canadian population consuming tap water from a distribution system meeting all water quality regulations. Because of the apparent vulnerability of this distribution system, this utility was selected as our main study site. The goal of this paper is to provide a brief overview of the work conducted and to summarize the major findings of our 5-year investigation. Various publications are available for more details: Besner et al. $(2007,2008,2010)$ and Ebacher et al. (2010).

\section{Methodology}

\subsection{Description of study site}

The selected distribution system supplies water to approximately 380000 consumers from three water treatment plants (WTPs) serving specific network areas. The average daily demand for the entire system is $210000 \mathrm{~m}^{3} / \mathrm{d}$ and the total pipe length is approximately $1600 \mathrm{~km}$. Cast-iron and ductile iron pipes represent $76 \%$ of the total pipe length, and pre-stressed concrete and PVC represent approximately $10 \%$ each.

Only one specific network area (mostly supplied from a single treatment plant) was selected for this study. However, there is no distinct pressure zone in the system such that the boundaries of each WTP zones of influence may move according to consumer demands. Apart from the clearwells and high-pressure pumps at the WTPs, there is no storage tank or pump station in the distribution system.

\subsection{Microbial characterization of potential sources of contamination}

The following sources of contamination were investigated as they can contribute to microbial intrusion in drinking water mains: (i) soil surrounding water mains, (ii) (ground)water (or trench water) surrounding water mains, and (iii) water from flooded air-vacuum valve vaults. The collected samples were assayed for microbial indicators of fecal contamination (Escherichia coli, Clostridium perfringens, enterococci, somatic and male-specific coliphages), total coliforms and aerobic endospores. A number of samples were assayed for human enteric viruses (culturable), enteroviruses and Bacteroidales fecal bacteria. Details of the detection methods are available in Besner et al. $(2008,2010)$.

\subsection{Pressure monitoring}

Continuous pressure monitoring was conducted for a period of 17 months (June 2006 to November 2007) at 19 different sites in the distribution system, for a total of 4104 days of logger data recorded (Besner et al., 2010). High-speed pressure transient data loggers (range: minus $11 \mathrm{~m}$ to $141 \mathrm{~m}(-15$ to $200 \mathrm{psi}$ )) were installed at the outlet of the WTP and on fire hydrants in the system to allow for the detection of transient low and negative pressures. These were recording between 1 to 4 pressure values per second, a resolution that is typical for studies characterizing the occurrence of low or negative pressure events in full-scale distribution systems (Kirmeyer et al., 2001; Friedman et al., 2004; Gullick et al., 2004; Fleming et al., 2006; Hooper et al., 2006). While other types of application such as inverse transient analysis, used for leak detection and system parameter calibration, requires higher frequency of pressure information ( $\mathrm{kHz}$ resolution), the current measuring frequency of 1 to $4 \mathrm{~Hz}$ is considered adequate for the application presented here, where the main interest is to detect the occurrence of negative pressure. In the context of the estimation of intrusion volumes into a full-scale distribution system, it is hypothesized that shorter duration $(<25 \mathrm{~ms})$ transient events, that would not have been captured here, would have a very low impact in terms of potential volume entering the system.

Because of freezing conditions during wintertime, fire hydrants could not be used and a reduced number of pressure sensors were in place in the distribution system $(n=2)$. Otherwise, there was between 9 to 12 sensors simultaneously recording pressure in the system.

\subsection{Transient analysis}

Transient analysis was performed using a commercially available software (MWH Soft, Arcadia, CA). This transient analysis framework is based on the Wave Characteristic Method (WCM) and includes the Discrete Vapor Cavity Model (DVCM) to simulate cavitation. Three low pressure events at the WTP, caused by power failures (short power interruptions) and resulting in the sudden shutdown of pumps, were modeled. The methodology is briefly presented here but more details are provided in Ebacher et al. (2010).

In order to reduce the model complexity and the computational cost, a preliminary step for the transient pressure model construction included the skeletonization of the extended period simulation (EPS) model from the water utility. From an original size of 29213 nodes and 32266 links, the model was reduced to 15965 nodes and 19044 pipes, while the total length of piping and the total demand remained unchanged. The only type of skeletonization operation conducted consisted in eliminating the interior nodes of all series pipes with the same attributes (e.g., diameter and material), if the elevation difference between the pipes end nodes was smaller than $2 \mathrm{~m}$. This $2 \mathrm{~m}$ elevation difference was selected 
as it is the minimum elevation difference that could be applied that would result in a skeletonized model with less than 20000 pipes, the maximum number of links allowed in the commercial transient analysis software used.

Typical wave velocity values were assigned to cast-iron mains $(1060 \mathrm{~m} / \mathrm{s})$, ductile iron mains $(1200 \mathrm{~m} / \mathrm{s})$, concrete mains $(600 \mathrm{~m} / \mathrm{s})$, PVC mains $(300 \mathrm{~m} / \mathrm{s})$ and steel mains $(1200 \mathrm{~m} / \mathrm{s})$. Although specific wave speed values are unknown, this approximation was considered more accurate than using a single wave speed value for the different pipe materials included in the model. In order to simulate each recorded low pressure event, transient conditions were created by simulating pump closures at the WTP using a change in the pump speed. The pump closure was set to start at $t=30 \mathrm{~s}$ after the start of the simulation and the simulation time was set to $300 \mathrm{~s}$ considering that: (i) the duration of the modeled pump shutdown event was approximately 2-3 min (time to reach back normal pressure) and, (ii) the distance between the water treatment plant (location of pump) and the end of the distribution system is approximately $20 \mathrm{~km}$. A pressure-sensitive demand formulation was used for all surge analyses.

The intrusion module of the transient analysis software was used to estimate the potential intrusion volumes at distribution system nodes based on a specified rate of leakage, in order to simulate intrusion through pipe leaks. Intrusion through submerged air-vacuum valves located in flooded vaults was modeled by using one-way feed tanks, where the water is only allowed to flow from the tank into the system. The software uses the orifice equation to compute the intrusion flow into an orifice:

$Q i=\frac{C_{d} \pi D^{2}}{4} \sqrt{2 g\left(H_{\mathrm{ext}}-H_{\mathrm{int}}\right)}$

where $Q i=$ intrusion flow; $C_{d}=$ coefficient of discharge; $D$ $=$ orifice diameter; $g=$ gravitational acceleration; $H_{\mathrm{ext}}=\mathrm{ex}-$ ternal head on pipe; and $H_{\text {int }}=$ internal line pressure. For intrusion using a leakage rate, the intrusion flow at a node is computed when the external head value (head of water above pipe - which is fixed by the user) is above the internal pipe pressure value. The leakage factor is used to set the size of the orifice. A leakage value of $20 \%$ was simulated along with an exit (or external) head of $1.4 \mathrm{~m} \mathrm{(2} \mathrm{psi).} \mathrm{When} \mathrm{com-}$ puting intrusion volumes through pipe leaks, it was assumed that none of the air-vacuum valves were submerged and these were modeled as surge protection devices. In the model, as their actual sizes were unknown, the air-vacuum valves were sized using the AWWA rule of thumb, which recommends a $25 \mathrm{~mm}$ inlet size per $300 \mathrm{~mm}$ of pipe diameter (AWWA, 2004). Resulting inlet diameters of 25,50 , and $75 \mathrm{~mm}$ were obtained. For simulating intrusion through submerged airvacuum valves, all air-vacuum valves located in the network studied area $(n=30)$ were assumed to be submerged under $0.5 \mathrm{~m}$ of water in the vault. A flooded vault is illustrated in Fig. 1.

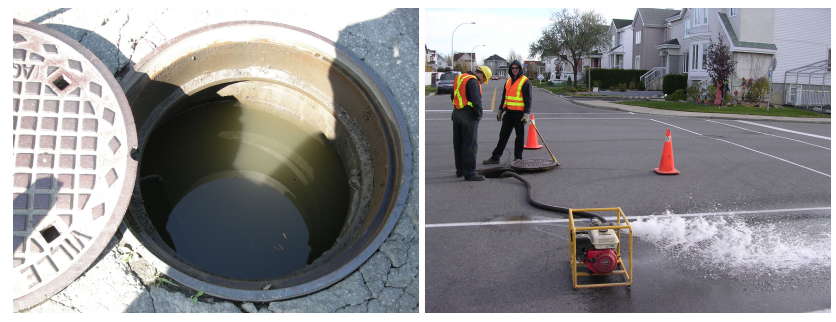

Figure 1. Flooded air-vacuum valve vault.

Table 1. Percentage of positive samples collected from potential contamination sources.

\begin{tabular}{lccc}
\hline Microorganism & Soil & $\begin{array}{c}\text { Trench } \\
\text { Water }\end{array}$ & $\begin{array}{c}\text { Water in } \\
\text { AV Vaults }\end{array}$ \\
\hline Aerobic endospores & $100 \%$ & $100 \%$ & $90 \%$ \\
Total coliforms & $67 \%$ & $100 \%$ & $100 \%$ \\
E. coli & $7 \%$ & $0 \%$ & $67 \%$ \\
C. Perfringens & $29 \%$ & $20 \%$ & $60 \%$ \\
Enterococci & NA & NA & $97 \%$ \\
Coliphages & $0 \%$ & $0 \%$ & $10 \%$ \\
Human enteric viruses (cell culture) & $0 \%$ & $0 \%$ & $0 \%$ \\
Enterovirus (CC-qRT-PCR) & NA & NA & $0 \%$ \\
Bacteroidales (general marker) & NA & NA & $73 \%$ \\
Bacteroidales (human marker) & NA & NA & $9 \%$ \\
\hline
\end{tabular}

CC-qRT-PCR: Cell culture quantitative reverse transcription polymerase chain reaction

AV: Air valve

NA: Not assayed

\section{Results}

\subsection{Microbial indicators of fecal contamination from potential contamination sources}

A total of 55 samples were collected from the external contamination sources investigated: 15 soil samples and 10 water samples from 15 pipe trenches at repair sites (Besner et al., 2008), and 30 water samples from 45 inspected airvalve vaults (Besner et al., 2010). While aerobic endospores and total coliforms were frequently detected in all sources, the frequency of detection of fecal indicator microorganisms was higher in the water samples collected from the air-valve vaults than in the soil/shallow groundwater surrounding water mains (Table 1). E. coli, C. perfringens, enterococci and Bacteroidales fecal bacteria were detected in more than $60 \%$ of the samples analyzed from the vaults. However, no culturable human enteric viruses were detected in the soil and trench water samples analyzed. Water samples from the vaults were also negative for viruses by both culture and molecular detection methods (19 samples out of 30 were assayed). 
The stagnant water found in the air-valve vaults could originate from two potential sources: infiltrated groundwater due to the vault (and water main) being located below the water table or street runoff following wet weather events. However, the relative contribution from these sources cannot easily be established. It is unlikely that some of the flooded vaults located at high elevation were located below the water table. The Bacteroidales fecal indicator results showed that the source of the microbial contamination in the vaults was mostly from animals (e.g. cats, dogs, mice, rats, birds, and other wildlife), which would indicate that street runoff could be a major source of contamination in those vaults.

The lower frequency of detection of indicators of fecal contamination in the soil and trench water samples could be explained by the distance between the sewer lines and the drinking water mains. Although this distance is not known, the sewer mains were not visible at any of the excavation sites but one.

In order to determine the level of contamination associated with each specific source (when microorganisms are present), data for each microorganism were compared to those observed in local river water and wastewater (Payment, 2003) and to soil and trench water from six US water systems (Karim et al., 2003). It was found that the level of fecal contamination in the soil, trench water and water from airvalve vaults, was more typical of levels found in untreated surface (river) water than wastewater (see Besner et al., 2010 for more details).

\subsection{Negative pressure events}

During the 17-month of pressure monitoring in the distribution system, a total of 18 negative pressure events were recorded (Besner et al., 2010). Fourteen of these events were isolated events (recorded at single locations in the system) while 4 events were recorded at more than one site. These latter events were all caused by a sudden shutdown of pumps at the WTP due to power failure. Typically, after the rapid pressure drop (from 63 to $3.5 \mathrm{~m}$ ( 89 to $5 \mathrm{psi}$ ) - on one event), it took from 2 to $3 \mathrm{~min}$ for the WTP pressure to reach back its original operating value. This type of event resulted in negative pressures in the distribution system lasting from 30 to $60 \mathrm{~s}$ at multiple monitoring sites, all located at higher ground elevation (the system does not have floating storage tanks).

The other main cause of negative pressure in this distribution system was the closure of a transmission main (Besner et al., 2007) which resulted in the supply of some parts of the studied area by a different WTP. Major hydraulic disturbances such as reversals in flow directions and low/negative pressures were experienced. Approximately 15000 customers were put under a preventive boil-water order during the repair work.

The lowest pressure recorded during the 17-month of highspeed pressure monitoring in the distribution system was $-5.1 \mathrm{~m}(-7.3 \mathrm{psi})$.

\subsection{Transient analysis and estimation of intrusion volumes}

Transient modeling was used to simulate three low pressure events recorded at the WTP, caused by a sudden shutdown of pumps due to power failure (Ebacher et al., 2010). Pressure predictions were obtained for these 3 events and were compared to field pressure measurements at 9 to 12 locations in the system. Intrusion volumes were estimated for only one of these events.

Comparison of predicted versus measured pressure profiles at numerous sites showed that the transient model was able to simulate downsurges fairly well as long as the pressure remained positive. However, for sites experiencing negative pressures, the amplitude of the modeled pressure drops was larger than that of the recorded pressure drops, indicating a greater energy dissipation in the real distribution system. At some monitoring locations, water column separation was even predicted but this was clearly not observed in the field. Measured data showed that the cavitation head was never reached at the monitoring locations, with $-5.1 \mathrm{~m}$ $(-7.3 \mathrm{psi})$ as the lowest pressure recorded at all sites. Model adjustments had to be provided as the overestimation of the downsurges amplitude is inconvenient and development of cavitation greatly modifies the shape of the pressure profile once it develops. Because numerous parameters, such as the presence of air in pipes, the allocation of demands (this distribution system is unmetered), the current interior pipe diameter, and the wave velocities are unknown, trying to calibrate a transient model with field data may rapidly get fastidious and complicated.

Adjustments were made to various model parameters in order to improve the model response. It was found that modifying the wave speed in cast-iron mains to $50 \%$ of its typical value $(1060 \mathrm{~m} / \mathrm{s})$ provided the greatest agreement with the measured field data. Ebacher et al. (2010) provide a detailed discussion of the uncertain parameters of the model, the potential causes of greater energy dissipation observed in the field, and expose the reasons behind the use of reduced wave speed in cast-iron mains to improve the model response. The wave speed reduction is used to mimic energy dissipation mechanisms that are not included in the model and is an artifice that is commonly applied (Wylie, 1992; Boyd et al., 2004; Friedman et al., 2004; Gullick et al., 2005), and is referred to as the modified MOC in Escarameia et al. (2005). The reduction of wave speed for model calibration may be crude and has several limitations, however, it still provides an effective mechanism for dissipating the excess model energy. As an example, Fig. 2 provides an illustration of recorded and simulated pressure profiles (with both typical and reduced wave speeds) at one monitoring site in the distribution system.

As it can be expected, the number of nodes experiencing negative pressure is reduced when a reduction of wave speed in cast-iron mains is applied, having an impact on the 
Table 2. Estimated intrusion volumes into the distribution system for two wave speed values in cast-iron mains.

\begin{tabular}{lccc}
\hline Pathway & \multicolumn{1}{c}{$100 \%$ Wave Speed } & \multicolumn{2}{c}{$50 \%$ Wave Speed } \\
\hline & Intrusion sites & $\begin{array}{c}\text { Total Intrusion } \\
\text { Volume (L) }\end{array}$ & $\begin{array}{c}\text { Intrusion sites } \\
\text { Total Intrusion } \\
\text { Volume (L) }\end{array}$ \\
\hline $\begin{array}{l}\text { Pipe Leaks Only } \\
(\% \text { of leakage }=20 \% \text {; External head }=1.4 \mathrm{~m})\end{array}$ & 1057 nodes & 79 & 604 nodes \\
$\begin{array}{l}\text { Submerged Air-Vacuum Valves (simultaneous } \\
\text { intrusion through pipe leaks is considered) } \\
(\text { External head }=0.5 \mathrm{~m})\end{array}$ & 8 AVVs & 190 & 2 AVVs \\
\hline
\end{tabular}

AVVs: Air-vacuum valves

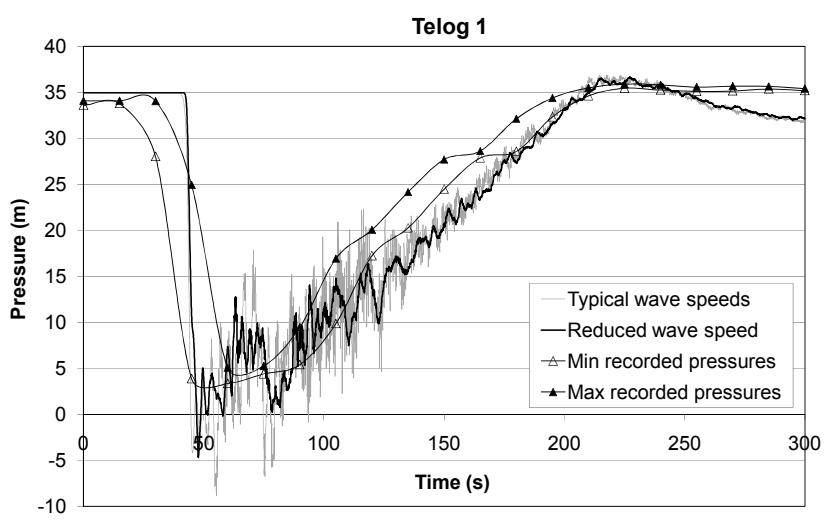

Figure 2. Comparison of pressures recorded at one distribution system site with pressures modelled with typical wave speeds and with a reduced wave velocity in cast-iron pipes (four pressure values per second were measured by the pressure recorders but only the minimum and maximum pressures over $15 \mathrm{~s}$ intervals were saved $(\Delta$ and $\mathbf{\Delta})$.

estimation of the potential volume of intruded water into the system (Table 2). It has to be noted that the software considers the same external pressure head over all pipes in the system, which is likely to provide some overestimation of the volume of water that could be intruded when a transient pressure event takes place in a real system. In this distribution system, vulnerable areas for negative pressure occurrence are located at higher elevations and it is known that pipes in these areas are not likely to be located below the water table.

Total intrusion volumes through a small number of submerged valves were found to be greater or similar to intrusion volumes through a very large number of pipe leaks. This is a disturbing result as the microbial characterization showed a higher frequency of detection of various fecal indicator microorganisms in the water from the vaults. Although the level of fecal contamination was more typical of that found in river water than in wastewater, this could still represent a significant risk for customers located directly downstream of such locations.

\section{Conclusions}

This paper summarizes an integrated set of studies conducted in the same distribution system where Payment et al. (1991, 1997) conducted their epidemiological studies. Field investigations including the characterization of potential sources of contamination, pressure monitoring, and hydraulic and transient analyses were conducted.

Bacterial indicators of fecal contamination were recovered more frequently in the water from flooded air-valve vaults than in the soil or water from pipe trenches. Because of the potentially large diameter of air-vacuum valve orifices, such result suggests that this intrusion pathway is a critical one when negative pressure occurs in this distribution system. Results of the long-term pressure monitoring showed that this distribution system was in fact susceptible to negative pressure events. While most of the recorded events were isolated, four transient events were associated with sudden pump shutdowns at the water treatment plant, affecting more than one measurement sites in the distribution system. The absence of floating storage makes this distribution system vulnerable to low/negative pressures at high elevations.

The extensive pressure monitoring results were used to develop a surge model that would accurately estimate transient pressure variations, in order to predict reasonable intrusion volumes and ultimately evaluate the risk that low/negative pressure events pose to public health. Transient analysis of a large and complex distribution system was found to be challenging with discrepancies between the energy dissipation simulated with the model and observed from field data. Our results show that one must be careful with the results obtained from transient simulations when no field data is available for verification. Other authors (McInnis and Karney, 1995; Friedman et al., 2004; Fleming et al., 2006) have also noted an overestimation of the computed downsurges.

Current work involves the development of a quantitative microbial risk assessment approach to evaluate the risk that intrusion events associated with such negative pressures may have on public health. Our experience indicates that inputs that are fed into a risk analysis model should be carefully 
analyzed, stressing the importance of collecting field data and not performing such an analysis on the sole basis of modeling outputs.

Acknowledgements. This research was supported by the Canadian Water Network, a center of excellence program funded by the Government of Canada. The authors would like to thank the staff from the water department and public works field crews from the participating utility for their valuable contribution and support and the staff from the NSERC Industrial Chair on Drinking Water at École Polytechnique for their precious help during field work.

Edited by: J. Boxall

\section{References}

ASCE: Infrastructure fact sheet, http://www.infrastructurereportcard.org/sites/default/files/ RC2009_drinkwater.pdf (last access: 15 April 2009), 2009.

AWWA: Manual M-11 Steel pipe: a guide for design and installation, Denver, CO, 2004.

Besner, M. C., Ebacher, G., Lavoie, J., and Prévost, M.: Low and negative pressures in distribution systems: do they actually result in intrusion?, Proc. 9th Annual International Symposium on Water Distribution Systems Analysis, ASCE-EWRI World Environmental and Water Resources Congress, Tampa, FL, 2007.

Besner, M. C., Lavoie, J., Morissette, C., Payment, P., and Prévost, M.: Effect of water main repairs on water quality, J. Am. Water Works Ass., 100, 7, 95-109, 2008.

Besner, M. C., Broseus, R., Lavoie, J., DiGiovanni, G., Payment, P., and Prevost, M.: Pressure monitoring and characterization of external sources of contamination at the site of the Payment drinking water epidemiological studies, Environ. Sci. Technol., 44, 269-277, 2010.

Boyd, G. R., Wang, H., Britton, M. D., Howie, D. C., Wood, D. J., Funk, J. E., and Friedman, M. J.: Intrusion within a simulated water distribution system due to hydraulic transients. II: volumetric method and comparison of results, J. Environ. Eng.-ASCE, 130, 7, 778-783, 2004.

Ebacher, G. Besner, M. C., Lavoie, J., Jung, B. S., Karney, B. W., and Prevost, M.: Transient modeling of a full-scale distribution system: comparison with field data, J. Water Res. Pl-ASCE., in press, doi:10.1061/(ASCE)WR.1943-5452.0000109, 2010.

Environment Canada: Leak Detection and Repair, http://www.ec. gc.ca/eau-water/default.asp?lang $=$ En $\& n=F 25 C 70 E C-1$ (last access: 2 June 2010), 2010.

Escarameia, M., Burrows, R., Little, M., and Murray, S.: Air Problems in Pipelines - A Design Manual, HR Wallingford Ltd, 2005.

Fleming, K. K., Dugandzic, J. P., LeChevallier, M. W., and Gullick, R.W .: Susceptibility of distribution systems to negative pressure transients, AWWARF Report, Denver, CO, 2006.
Friedman, M., Radder, L., Harrison, S., Howie, D., Britton, M., Boyd, G., Wang, H., Gullick, R., LeChevallier, M., Wood, D., and Funk, J.: Verification and control of pressure transients and intrusion in distribution systems, AWWARF Report, Denver, CO, 2004.

Gullick, R. W., LeChevallier, M. W., Svindland, R. C., and Friedman, M. J.: Occurrence of transient low and negative pressures in distribution systems, J. Am. Water Works Ass., 96, 11, 52-66, 2004.

Gullick, R. W., LeChevallier, M. W., Case, J., Wood, D. J., Funk, J. E., and Friedman, M. J.: Application of pressure monitoring and modeling to detect and minimize low pressure events in distribution systems, J. Water Supply Res T., 54, 2, 65-81, 2005.

Hooper, S. M., Moe, C. L., Uber, J. G., and Nilsson, K. A.: Assessment of microbiological water quality after low pressure events in a distribution system, Proc. 8th Annual Water Distribution Systems Analysis Symposium, Cincinnati, OH, 2006.

Karim, M. R., Abbaszadegan, M., and LeChevallier, M.: Potential for pathogen intrusion during pressure transients, J. Am. Water Works Ass., 95, 5, 134-146, 2003.

Kirmeyer, G. J., Friedman, M., Martel, K., Howie, D., LeChevallier, M., Abbaszadegan, M., Karim, M., Funk, J., and Harbour, J.: Pathogen intrusion into the distribution system, AWWARF Report, Denver, CO, 2001.

LeChevallier, M. W., Karim, M., Aboytes, R., Gullick, R., Weihe, J., Earnhardt, B., Mohr, J., Starcevich, J., Case, J., Rosen, J. S., Sobrinho, J., Clancy, J. L., McCuin, R. M., Funk, J. E., and Wood, D. J.: Profiling water quality parameters: from source water to the household tap, AWWARF Report, Denver, CO, 2004.

McInnis, D. and Karney, B. W.: Transients in distribution networks: field tests and demand models, J. Hydraul. Eng-ASCE, 121, 3, 218-231, 1995.

NRC.: Drinking water distribution systems: assessing and reducing risks, The National Academies Press, Washington, DC, 2006.

Payment, P., Richardson, L., Siemiatycki, J., Dewar, R., Edwardes, M., and Franco, E.: A randomized trial to evaluate the risk of gastrointestinal disease due to consumption of drinking water meeting current microbiological standards, Am. J. Public Health, 81, 6, 703-708, 1991.

Payment, P., Siemiatycki, J., Richardson, L., Renaud, G., Franco, E., and Prevost, M.: A prospective epidemiological study of gastrointestinal health effects due to the consumption of drinking water, Int. J. Environ. Heal. R., 7, 1, 5-31, 1997.

Payment, P.: Enlèvement des microorganismes pathogènes et des bactéries indicatrices par les stations de traitement des eaux usées municipales situées sur la rivière des Mille îles, Programme d'aide à la recherche et au développement en environnement (PARDE), Ministère de l'Environnement du Québec, 2003.

WHO: Leakage Management and Control - A Best Practice Training Manual, World Health Organization, Geneva, 2001.

Wylie, E. B.: Low void fraction two-component two-phase transient flow, in: Unsteady flow and fluid transients, edited by: Bettess, R. and Watts, J., HR Wallingford, Durham, UK, 3-9, 1992. 